\title{
The CEFR Companion Volume: between research-based policy and policy-based research
}

The Common European Framework of Reference for Languages (CEFR - Council of Europe 2001) has fundamentally impacted language teaching and assessment in Europe (Barni 2015; Figueras 2012) and across the globe (Byram \& Parmenter 2012). But the world has changed since its publication, and the internet has transformed communication. And so, for this reason and others, the CEFR has been updated and expanded with the Companion Volume $(\mathrm{CV})$. In this contribution we gauge the CV's merits by the degree to which it takes into account fundamental criticism to the CEFR. We argue that the CV incorporates comments on the CEFR that suit its original purpose but largely disregards fundamental criticism. As such, the CV continues along the lines of the CEFR, for better and for worse.

\section{Background to the CEFR and the Companion Volume}

The history of the CEFR is entangled with the history of the Council of Europe (CoE) - the organization that engendered it. Founded in the wake of the Second World War, the $\mathrm{CoE}$ aims to protect human rights, the rule of law, and parliamentary democracy in its 47 member states. As the CoE strives to advance mutual understanding between nation states, language education, communication and multilingualism are central to its mission. And so, in 1959 the CoE launched an initiative to support communicative language teaching in Europe, which galvanized into the Modern Languages Project in the 1970s. This project was to investigate the possibility of developing a pan-European unit-credit system that would allow language learners to document their foreign language qualifications in a modular way. These efforts led to the Threshold Level (van Ek 1975); a description of the day-to-day linguistic challenges migrants faced when living in a foreign country. Since the Threshold level was so popular, the authors were asked to develop additional levels. Initially, they were reluctant to do, since they did not want to apply a compartmentalized, level-based logic to language learning (Trim 2012). Nevertheless, in order to advance communicative approaches to language learning, Vantage and Waystage were published in subsequent years. 
As such, when the CEFR was published in 2001, it incorporated previously established linguistic descriptions such as Threshold (B1), Vantage (B2) and Waystage (A2), supplemented with newer levels and descriptors, bound together in an overarching framework. The CEFR thus introduced a vertical or hierarchical dimension to the levels by mapping them onto a common scale. Additionally, the CEFR continued to promote the mobility of people and ideas, and lifelong learning, while aspiring to create a common metalanguage to talk about language proficiency across educational systems and international borders (Council of Europe 2001).

Within a decade after its launch, the CEFR became the most widely used language proficiency framework worldwide, impacting language policy, language curricula and language tests across the globe (Figueras 2012). It is not surprising that a framework this influential attracted scrutiny and criticism. Criticism typically focused either on the CEFR's use, or on its scientific foundations. Usage-based criticism has highlighted that the CEFR allows policy makers to easily use language proficiency levels as gatekeepers without a thorough needs analysis (Barni 2015). Scientific critique has focused on the development and validation of the level descriptors (Alderson 2007; Fulcher 2004), on theoretical gaps in the CEFR's foundation (Hulstijn 2007), or on the impressionistic wording of the level descriptors (Alderson 2007). Still others have questioned why multilingualism received comparatively little attention in the scales (Krumm 2007) and why the CEFR appeared to uphold a native speaker norm (Barni 2015; McNamara 2014).

In spite of the criticism, the CEFR has received a remarkable uptake. The purpose of the recently published $\mathrm{CV}$ is thus not to replace the highly popular CEFR, or to change its status (Council of Europe 2018), p. 23), but to expand, clarify and update it. Thereto, the CV provides new scales for language activities that were not covered in the CEFR (e.g., online communication, mediation) and presents more elaborately defined plus levels, pre-A1 levels and $\mathrm{C}$ levels. The CV also focuses on plurilingualism and foregrounds mediation. The new descriptors for sign language users and young learners are another important addition, but they are not included in the main text of the CV and will not be discussed here.

\section{Innovations and (missed) opportunities}


When considering the merits of the $\mathrm{CV}$, perhaps the first issue to tackle, is its status. If the CV "does not change the status" of the CEFR (Council of Europe 2018, p. 23), inconsistencies between the CEFR and the CV would effectively establish two sets of descriptors. Perhaps to avoid such a scenario, most of the CEFR scales are included in the CV in their original form, even though an update might have been warranted. In 2019, some descriptors read as outdated (e.g., "watching tv news"), Eurocentric or value-laden (e.g., "propose a toast" at A1). Moreover, their focus on target language use contexts such as leasure, travel, and especially academia (e.g. ) may diminish their applicability in a global community of language learners, where less than ten percent has a university degree (Barro \& Lee 2013).

Not all descriptors have remained unchanged, however, and one of the most noticeable changes relates to the use of the term native speaker, which has been replaced with speakers of the target language. Even though this change corresponds to the current orthodoxy in applied linguistics (Houghton et al. 2018), it does present a problem. The term native speaker, as used in the CEFR, implies a competent, fluent language user who is able to convey and comprehend nuanced and idiomatic language use. The $\mathrm{CV}$, however, does not specify the proficiency level of Speakers of the target language. It is unclear whether the term refers to people who speak the target language at any level, or to proficient users only. The B2 descriptor of the Conversation scale implies that the latter is the case, but the issue is never explicitly addressed. One could wonder whether adopting the term speakers of the target language represents a refutation of the L1/L1 dichotomy used in SLA, but that does not seem to be the case, since the new term is quite simply implemented in pre-existing scales without a clear rationale supporting its use.

A second major change in the $\mathrm{CV}$ is the focus on mediation - an activity whereby "the user/learner acts as a social agent who creates bridges and helps to construct or convey meaning, sometimes within the same language, sometimes from one language to another" (Council of Europe 2018, p. 103). Mediation was already discussed in the CEFR, but in the $\mathrm{CV}$ it has become such a central concept that it is listed as one of the four primary Communicative language activities and strategies. Considering mediation as a separate language activity should perhaps be seen as a value statement rather than as a real theoreticalconceptual innovation. Theoretically, mediation is loosely defined and vaguely demarcated 
in the CV. It is stated - not argued or supported by data - that subdividing communication into reception, production, interaction and mediation is "closer to real-life language use, which is grounded in interaction in which meaning is co-constructed" (Council of Europe 2018, p. 31), but if this true, it remains unclear why the mediation scales are presented as speaker-centred unidirectional can-do statements. Moreover, since mediation must logically include at least two other communicative activities to take place, it is conceptually superfluous (see Wittgenstein 1922 on Ockham's razor). The rather puzzling diagram on p. 32 does little to convice the reader of the conceptual necessity of mediation.

Because of the theoretical and conceptual shakiness of mediation, operationalizing it as a rating criterion will present substantial challenges for test developers. They will need to consider how to reliably and validly score a somewhat vague construct that is impossible to disentangle from other constructs. These fundamental objections notwithstanding, mediation does fit the CEFR's communicative approach, links in with the CoE's values, and may lead to more communicative language teaching and testing. In fact, language testing organizations have already started developing integrated, communicative language tasks in response to the mediation scales. Even so, it remains to be seen if and how mediation will be scored and operationalized.

Mediation has been subdivided into more than twenty subscales, and the CV includes over 30 new or redeveloped scales. These proficiency scales are introduced by a brief definition. In itself, that is a useful addition, but due to the sometimes hermetic writing style these introductions are rather hard to grasp. Users who were troubled by the style of the CEFR (Martyniuk \& Noijons 2007), will find the CV a challenging read as well. The sometimes vague and impressionistic language that was a problem for language testers working with the CEFR (Alderson 2007), persists in the CV.

On a more strategic level, the attention devoted to proficiency scales in the CV marks a striking shift. CEFR proponents have often stressed that the scales are illustrative only and have become more important than originally intended (North 2014; Trim 2012). Consistency with this argument would have dictated that the CV focused less on the scales, not more. Nevertheless, it appears that the authors of the CV have embraced the idea that for most users, the scales are the framework (Martyniuk \& Noijons 2007). 
The centrality of the scales in the CV warrants a closer look at their methodological foundation. The authors have provided ample documentation (e.g., North \& Piccardo 2016) to explain how they were designed and validated. These reports, however, do not justify why the validation and revision relied on language professionals judging and mapping descriptors in a contextual vacuum. As far as is clear, no learner performances were involved in the construction or calibration of the new scales, and neither were learners themselves. For a document that claims to support learner empowerment, this is somewhat contradictory. Moreover, even though the authors signal the danger of circularity in validation processes, it is unclear how circularity was avoided when participants had to demonstrate their knowledge of the CEFR before taking part in the validation of new descriptors.

Overall, one wonders why the CV remains true to the CEFR's approach to scale development when this methodology has received such fundamental criticism (Alderson 2007; Fulcher 2004). Studies have repeatedly shown that the original CEFR scales are largely unsuitable to reliably compare performances across or within educational systems (Deygers, Carlsen, et al. 2018). It is unclear how the CV will bring us closer to achieving this goal, when they replicate a disputed methodology.

Related to the topic of empirical robustness, the CV contains a number of statements that may be in line with its values, but are scientifically dubious. One such statement is that plurilingualism has "been shown to result in a number of cognitive advantages" (Council of Europe, 2018, p. 28) - a contested claim at best (see Lehtonen et al. 2018). Also, asserting that "vocabulary range is generally acquired through reading widely" (Council of Europe 2018, p. 132) would have benefited from more nuance (see Laufer 2006).

Lastly, while the CV incorporates some conceptual criticism on the CEFR, it remains silent on its political use. The authors appear agnostic about the widespread use of CEFR levels to control the free movement of people in migration contexts (Byram \& Parmenter 2012). Surely, the CV would have been an appropriate channel to condemn any use of the CEFR that is antithecal to the core values of the CoE. That the CV refrains from doing so, is a missed opportunity. 


\section{Conclusion: too big to fail?}

As a policy text the CEFR has proven remarkably successful, and from a policy perspective, it is logical that the CV stays true to its predecessor. The CV is not only a policy text however, but also a quasi-scientific publication, invoking empirical backing and research methods. Scientifically, the CV's value is less straightforward. Philosophy of science posits that a theory can only be considered scientific, if newer versions rely on stronger empirical evidence and if they demonstrate a willingness to incorporate fundamental criticism (Hansson 2017). The CV, however, leaves many contentious aspects of the CEFR untouched and does not truly engage with well-founded criticism. Neither does it refer to the many empirical studies that have been conducted since 2001, or to SLA theories that could have enriched the framework (e.g., Hulstijn 2015). Thus, while a resistance to change is understandable for a policy document, from a scientific perspective it is disqualifying. The revolution of the CEFR, called for by McNamara (2014), will have to wait another day.

\section{References}

Alderson, C. (2007). 'The CEFR and the Need for More Research', The Modern Language Journal, 91/4: 659-63.

Barni, M. (2015). 'In the name of the CEFR: Individuals and Standards'. Spolsky B., InbarLourie O., \& Tannenbaum M. (eds) Challenges of language education and policy. Making space for people, pp. 40-52. Routledge: New York.

Barro, R., \& Lee, J. (2013). 'A new data set of educational attainment in the world, 1950$2010^{\prime}$,

Journal of Development Economics, 104: 184-98.

Byram, M., \& Parmenter, L. (Eds). (2012). The Common European Framework of Reference: The Globalisation of Language Education Policy. Buffalo: Multilingual Matters.

Council of Europe. (2001). Common European Framework of Reference for Languages: Learning,

Teaching, Assessment. Strasbourg: Council of Europe.

- - . (2018). Common European Framework of Reference for Languages: Learning, teaching, assessment. Companion volume with new descriptors. Strasbourg: Council of Europe. 
Deygers, B., Carlsen, C., Saville, N., \& Van Gorp, K. (2018). 'The Use of the CEFR in Higher Education: A Brief Introduction to This Special Issue', Language Assessment Quarterly, 15/1: 1-2.

Figueras, N. (2012). 'The impact of the CEFR', ELT Journal, 66/4: 477-85.

Fulcher, G. (2004). ‘Deluded by Artifices? The Common European Framework and Harmonization', Language Assessment Quarterly, 1/4: 253-66.

Hansson, S. (2017). 'Science and Pseudo-Science'. Zalta E. (ed.) The Stanford Encyclopedia of Philosophy. Metaphysics Research Lab, Stanford University: Stanford, CA.

Hulstijn, J. (2007). 'The Shaky Ground Beneath the CEFR: Quantitative and Qualitative Dimensions of Language Proficiency', The Modern Language Journal, 91/4: 663-667.

- - . (2015). Language Proficiency in Native and Non-native Speakers: Theory and research. Amsterdam ; Philadelphia: John Benjamins.

Krumm, H.-J. (2007). 'Profiles Instead of Levels: The CEFR and Its (Ab)Uses in the Context of Migration', The Modern Language Journal, 91/4: 667-669.

Laufer, B. (2006). 'Vocabulary Acquisition in a Second Language: Do Learners Really Acquire Most Vocabulary by Reading? Some Empirical Evidence', Canadian Modern Language Review, 59/4: 567-87.

Lehtonen, M., Soveri, A., Laine, A., Järvenpää, J., de Bruin, A., \& Antfolk, J. (2018). ‘Is bilingualism associated with enhanced executive functioning in adults? A metaanalytic review', Psychological Bulletin, 144/4: 394-425.

Martyniuk, W., \& Noijons, J. (2007). 'Executive summary of results of a survey on the use of the CEFR at national level in the Council of Europe Member States.' Strasbourg: Council of Europe Language Policy Division.

McNamara, T. (2014). ‘30 Years on-Evolution or Revolution?', Language Assessment Quarterly, 11/2: 226-32.

North, B. (2014). 'Putting the Common European Framework of Reference to good use', Language Teaching, 47/02: 228-49.

North, B., \& Piccardo, E. (2016). 'Developing Illustrative Descriptors of Aspects of Mediation for the Common European Framework of Reference (CEFR): A Council of Europe Project', Language Teaching, 49/3: 455-9.

Trim, J. (2012). 'The Common European Framework of Reference for Languages and its 
background: A case study of cultural politics and educational influences'. Byram M.

\& Parmenter L. (eds) The Common European Framework of Reference: The Globalisation of Language Education Policy, pp. 14-36. Multilingual Matters: Buffalo.

van Ek, J. (1975). 'Systems Development in Adult Language Learning: The Threshold Level in a European-Unit/Credit System for Modern Language Learning by Adults'. Strasbourg: Council of Europe.

Wittgenstein, L. (1922). Tractatus logico-philosophicus. New York: Cosimo. 